\title{
MUSCULOSKELETAL DISORDERS IN BROADCASTING ENGINEERS: THE ROLE OF ERGONOMIC FACTORS AND WORK ORGANIZATION
}

\author{
K. Vangelova, B. Tzenova and V. Stanchev \\ National Center of Public Health and Analyses - Sofia, Bulgaria
}

Summary. The rate of musculoskeletal disorders is increasing in white collar workers and often is discussed in relation to ergonomic and work organization issues. The aim of the study was to follow the rate and determinants of musculoskeletal disorders in broadcasting engineers under shift work. Job analysis and ergonomic evaluation of the workplaces of 168 broadcasting engineers, working different shift work schedules, was carried. The self reported working conditions, psychosocial and ergonomic factors were followed. Questioning for distribution and localization of musculoskeletal complaints and diagnosed musculoskeletal disorders was carried. Data were analyzed with variation, correlation and regression analysis. A lot of ergonomic and work organization problems, simultaneous work on two monitors, changes of workplace during the shift were found. More than $50 \%$ of the employees were not content with shift work schedules, $38.7 \%$ worked often under time pressure and $23.8 \%$ in non-ergonomic work posture. A high incidence of musculoskeletal complaints mainly in the region of the back and neck was found. $35.1 \%$ of the employee reported musculoskeletal disorders, determined by nonergonomic work posture, problems in shift work schedules, lack of control and decision making in a highly significant model. Measures for improving workplace ergonomics and work organization were proposed in order to reduce stress, fatigue and health risks in broadcasting staff.

Key words: ergonomic problems, shift work, stress, musculoskeletal disorders

\section{INTRODUCTION}

- Whe injuries of the musculoskeletal system have a multifactorial etiology [1], and it is of great importance that the work-related musculoskeletal disorders are preventable. A lot of ergonomic factors such as repetitive 
movements, applied force, speed of work, static load are discussed as a cause for musculoskeletal disorders in the neck, back and upper extremities [2, 3, 4]. The musculoskeletal complaints are the earliest symptoms of the disorders and often precede their development with more than decade. The rate of musculoskeletal complaints is increasing in white collar workers and they are more common even than the complaints due to stress and fatigue at work. Ergonomic factors and variety of organizational factors as high demands and low control are associated with higher frequency of musculoskeletal complaints in the region of the neck/shoulders $[5,6]$.

The tasks of broadcasting and sound-recording engineers in radio production are mainly mental, pose high demands and require operation with technical equipment. The work posture is mainly sitting and work organization includes shift work. The data concerning the effect of ergonomic factors and work organization on musculoskeletal disorders of broadcasting and sound-recording engineers are scarce. Our earlier data showed high rates of musculoskeletal complaints in a small group of sound-recording engineers [7], but the rates of musculoskeletal disorders were not followed.

The aim of the study was to follow the rate and determinants of musculoskeletal disorders in broadcasting and sound-recording engineers in radio production.

\section{METHODS}

The study included 168 broadcasting and sound-recording engineers with a mean age of $48 \pm 9.9 \mathrm{yrs}$ and length of service $24.1 \pm 10.4 \mathrm{yrs}$. The studied employees worked different shift work schedules, as follows: 82 employees worked two shift system (morning shift from 07:30 a.m. to 03:30 p.m. and afternoon shift from 02:30 p.m. to 10:30 p.m.) with weekly rotation and 88 employee covered 24-hour broadcasting with fast rotating shifts, with two options forward and backward rotating shifts, as earlier described [8].

Job analysis and ergonomic evaluation of the workplaces was carried through observation, interviewing and chronometry of the basic workplaces. The static load of the musculoskeletal system and the risk in maintaining work posture is based on chronometric measurements of the time for maintaining an appropriate work posture, expert assessments and classification of work postures by type and characteristics, an analysis of some biomechanical parameters of the work posture (work angles of the joints, angles of bending and twisting of different parts of the body, etc.). A questionnaire for the self-ratings of the employees for the work posture and workplace (work surface, work chair, leg space) and unfavorable work activity factors has been applied.

The self-reported working conditions, psychosocial factors ( 21 questions), stress and strain sources (23 questions) were studied and described in details earlier [9].

The incidence and localization of musculoskeletal complaints was followed with the standardized Scandinavian questionnaire [10]. The diagnosed by physician musculoskeletal diseases were reported, as follows: disorders of upper back or cer- 
vical spine, lower back, musculoskeletal disorder affecting the arms and feet, pain radiating from the back to the legs, rheumatoid arthritis and other musculoskeletal disorders.

Statistical analysis covered variation, correlation and regression analysis.

\section{RESULTS}

\section{Work activities analysis}

The working rooms are a kind of studio complexes, cabins and offices. The typical workplaces for sound-broadcasting and -recording can be classified as "computerized workplace", where a virtual sound-broadcasting and -recording panel is situated on two monitors. This system is based on one or more computers and is operated by one employee for life show recordings or montage work.

The sound-broadcasting and -recording production is realized by different musical and speech programs on tape-recorders and on computers. The basic sound-recording work is carried on computers (60\% of the recordings), thus the work with video display units is often more than 4 hours daily. After the recording is completed, it has to be assembled and mixed. The duration of the recordings varies from 3 to 4 hours. For musical and speech program recordings and participation in life shows specialized equipment is used and the recording is carried on computers with continuous control of the signal parameters. Special panels for the processing and transportation of the sound signals are used. The duration of participation in life show broadcastings is from 1 to 3 hours daily during the shift. For another part of the working time additional activities are done such as supply of sound-carriers from the stores, meetings and consultations, check up for the fitness of different materials, etc.

The specificity of the work determines the work tasks. Thus in practice the available staff is distributed according to the needs of the production at the moment. This contributes to the diversity of tasks and a high degree for mutual replacements of the staff, concerning mainly the workplaces and less the tasks.

\section{An ergonomic assessment of the workplace}

The employees had no permanent work stations, but in both, sound-broadcasting and -recording production had to change two or more workplaces during the shift, for example, recording in a studio, life show broadcasting and recording in another studio. In fact, a possibility for adaptation of the employees to a workplace in relation with their specific needs and requirements is lacking.

The work chair is one of the few elements of the workplace that can be adapted to the requirements of the employees, but during the observations we carried, the employees did not adapt the work chair at the beginning of the work, in spite the chairs were used by both sexes and employees with different anthropometric characteristics.

In the part of the workplaces the work is carried on a computer system for sound recording (with one or two monitors). Although there is sound-mixing panel at 
the workplace, the whole work is done on the computer configuration. In this system special software is used, which does not include setting up, but the monitors provide stable and clear picture. The workplaces cannot give the possibility to turn or tilt the monitor in order to have the best work posture. During broadcasting in a life show a more complex motor activity is performed under time pressure (work with slide rider, panel controllers, etc.), following also a monitor. The blinks on the monitor screen do not make difficult the reading of the text and are negligible.

The postures during sound montage with two monitors are often non-ergonomic. The picture on the computers contains quite many elements (a virtual soundrecording studio), which should be clearly differentiated. The lack of possibility to change the organization of the workplace is the main reason for non-ergonomic work postures.

Another problem is a lack of space for the legs when using two monitors because of the inappropriate work furniture. The place for the legs is in the center and is considered for work with a mixing panel, but not with a computer. As a consequence twisting the back and work without support for the hands can be observed. The edge of the work surface is used as a wrist support, known to be a risk factor for appearance of complaints in the region of wrists and fingers.

On the base of self-ratings according to $35 \%$ of the employees the size of the workplace is not enough. $34 \%$ of the respondents considered the space for the legs under the plot insufficient, $25 \%$ - impossible to adjust the height of the work chair, and $42 \%$ - impossible to adjust the height and tilt of the chair back.

\section{Strain at work}

The most distributed sources of strain, as earlier described [9], were the following: inadequate payment for the carried work (84.8\%), poor condition of the air $(70.9 \%)$, working with a lot of people $(66.7 \%)$, noise at work place $(65.5 \%)$, being not content with the shift work schedules (63.6\%), working in non-ergonomic work posture $(57.7 \%)$, lack of recognition for a well done job $(56.4 \%)$, time pressure $(46.1 \%)$, a lot of responsibilities, low latitude for decision making (38.8\%), overtime work $(33.3 \%)$.

\section{Musculoskeletal complaints}

A high frequency of musculoskeletal complaints has been established in the studied group of employees. Only $25.3 \%$ of the inquired subjects have no complaints, $14.7 \%$ have one complaint, $18.2 \%$ - two complaints and $41.8 \%$ - three or more musculoskeletal complaints.

Figure 1 shows the distribution of complaints in body regions. The percentage of the employees with musculoskeletal complaints in the region of the neck $(49.1 \%)$ is the highest, followed by complaints in the back (47.9\%) and low-back regions $(39.5 \%)$. The number of the musculoskeletal complaints correlates significantly with the complaints of insufficient leg space under the worktop ( $r=.36 p=0.001)$, a key element for working in non-ergonomic posture, connected with twisting of the body and lack of sufficient support for the hands. The insufficient space for the legs under 
the worktop correlates with the aches complaints in the regions of the shoulders, back and hands. A significant correlation between the duration of work with a video display (4 or more than 4 hours daily) with the total number of musculoskeletal complaints $(r=.28, p=0.01)$ and aches complaints in the region of the neck $(r=.28, p$ $=0.01$ ) has been established. The presence of blinks on the monitors is associated with the complaints in the region of the neck $(r=.26, p=0.02)$. The number of musculoskeletal complaints (Table 1) was predicted by insufficient time for work breaks and specialized length of service $(p=0.003)$, while the possibility to regulate the height and tilt of the chair back and the insufficient time for work breaks were significantly associated with the presence of pains in the region of the neck and shoulders $(p=0.006)$.

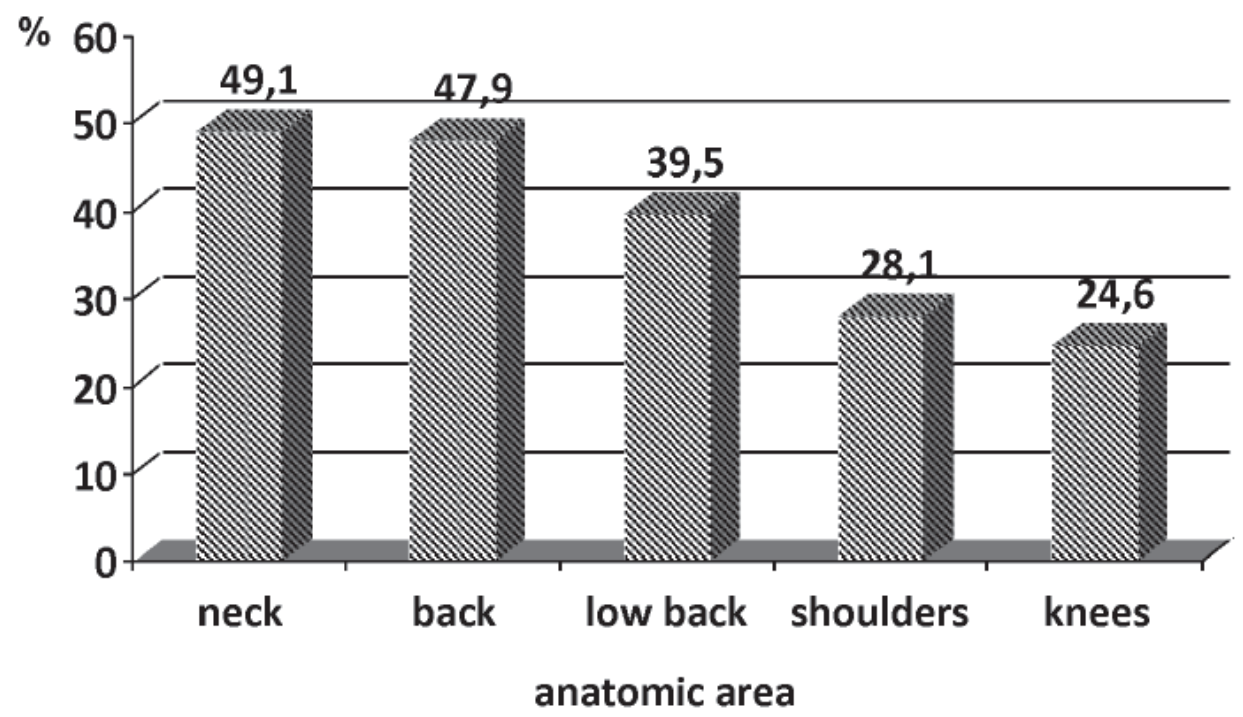

Fig. 1. The rates of musculoskeletal complaints in the broadcasting and sound-recording engineers

\section{Musculoskeletal disorders}

$35.1 \%$ of the employee reported diagnosed by physician musculoskeletal disorders as follows: $18.5 \%$ - one diagnosed musculoskeletal disorder, $10.7 \%$ - two disorders, $11 \%$ - more than 3 disorders. The rates of musculoskeletal disorders were significantly higher with the aging employee (> 45 years) $(c 2(5,168)=12,124$, $p=0.033$ ), but no significant gender differences were found. Leading position of the diagnosed musculoskeletal disorders (Figure 2) was held by the disorders of upper back or cervical spine ( 28 cases $-16.7 \%$ ), followed by disorders of lower back ( 27 cases $-16.1 \%)$, musculoskeletal disorders affecting the arms and feet (20 cases $-11.9 \%$ ), pain radiating from the back to the legs (14 cases $-8.3 \%$ ), rheumatoid arthritis (6 cases $-3.6 \%$ ) and other musculoskeletal disorders (9 cases $-5.4 \%$ ). 
The musculoskeletal disorders were determined by non-ergonomic work posture, problems in shift work schedules, lack of control and decision making in a highly significant model (Table 1).

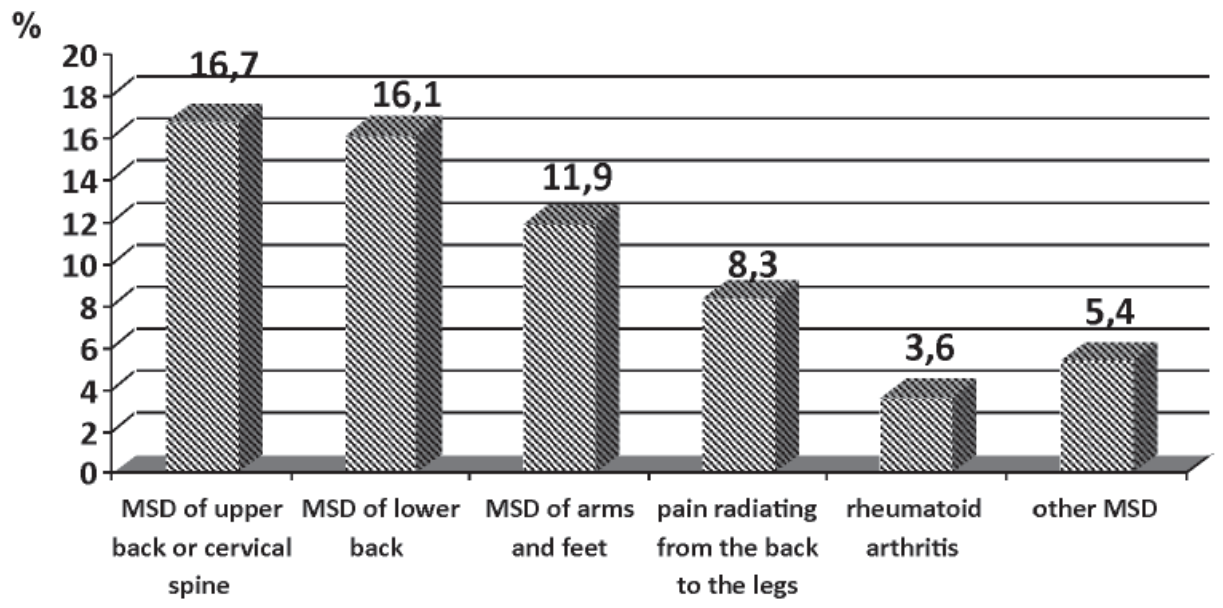

\section{Musculoskeletal Disorders (MSD)}

Fig. 2. The rates of musculoskeletal disorders in the broadcasting- and sound-recording engineers

Table 1. Stepwise multiple regression analysis for the musculoskeletal complaints and disorders as independent variables

\section{Variables}

Dependent

1. Number of musculoskeletal complaints

\section{Predictor}

Insufficient time for work breaks

Specialized length of service b .740

.555 $\mathbf{t}$

p

$r^{2}$ for the model $=73.50 \%, F=11.195, p=0.003$

\begin{tabular}{lllll}
\hline $\begin{array}{l}\text { 2. Pains in the neck and } \\
\text { shoulders }\end{array}$ & Height and tilt of the chair back & .688 & 3.518 & 0.004 \\
& Insufficient time for work breaks & .522 & 2.670 & 0.02
\end{tabular}

$r^{2}$ for the model $=49.70 \%, F=7.913, p=0.006$

\begin{tabular}{|c|c|c|c|c|}
\hline \multirow[t]{4}{*}{ 3. Musculoskeletal disorders } & Non-ergonomic work posture & .673 & 5.675 & 0.000 \\
\hline & Strain by shift work schedules & .640 & 5.281 & 0.000 \\
\hline & Control & .319 & 2.858 & 0.000 \\
\hline & Decision making & -.304 & -2.366 & 0.028 \\
\hline
\end{tabular}




\section{DISCUSSION}

Our data show that $74.7 \%$ of the studied subjects have musculoskeletal complaints and in $46 \%$ of them the complaints are three or more than three. One of the prerequisites for the considerable number of musculoskeletal complaints, mainly in the regions of the back and neck, are the ergonomic problems at the workplaces - numerous complaints from the work chair, size of the workplace, lack of space for the legs. The complaints in the region of the back are associated mainly with the work posture, non-ergonomic work and rest organization, inadequate duration and problems in organization of the work tasks, etc. [11,12,13], while the ones in the region of the neck with non-ergonomic work posture, the presence of uncorrected refractional abnormalities, strain $[11,14,15]$. Our findings confirm these data showing that the height and tilt of the chair back and the insufficient work breaks are predictors for pains in the regions of the neck and shoulders. The musculoskeletal complaints in the region of the back are significantly associated with the complaints of blinks on the screen of the monitors. In case of impossibility to adjust the parameters of the workplace the employees work in non-ergonomic postures, as they try to find a good vision angle in which the blinks are less and the picture on the monitor is of good quality - clear and easy to read.

$35.1 \%$ of the employee reported diagnosed by physician musculoskeletal disorders with highest rates of disorders of upper back or cervical spine, followed by disorders of lower back, musculoskeletal disorders affecting the arms and feet, pain radiating from the back to the legs, rheumatoid arthritis and other musculoskeletal disorders. The musculoskeletal disorders were determined by non-ergonomic work posture, problems in shift work schedules, lack of control and decision making in a highly significant model. The etiology of musculoskeletal disorders is multifactorial, but the age definitively is of importance for the high rates of musculoskeletal disorders in the studied group, besides it is not a significant predictor in the regression model. We consider that it is due to the fact that the group is homogeneous in age, and a great deal of the investigated subjects is over 40 -year old $(79 \%)$.

\section{CONCLUSION}

In conclusion, the ergonomic assessment determined a number of inadequacies at the workplaces in relation to its equipment and organization - unsuitable chairs and work surfaces, inconvenient work postures, problems in arrangement of the workplaces, etc. More than $50 \%$ of the employees were not content with shift work schedules, $38.7 \%$ worked often under time pressure and $23.8 \%$ in non-ergonomic work posture. The found ergonomic and work organization problems, the non-ergonomic work posture, the lack of determined work breaks and the age of the studied group are the most probable reasons for the considerable number of musculoskeletal complaints and disorders. Measures for improving workplace ergonomics and work organization were proposed to reduce health risks in the broadcasting and sound-recording staff, including the risks of musculoskeletal disorders. 


\section{REFERENCES}

1. Lanfranchi J-B, Duveau A. Explicative models of musculoskeletal disorders (MSD): From biomechanical and psychosocial factors to clinical analysis of ergonomics. European Reviews of Applied Psychology 2008; 58; 4: 201-213.

2. Eltayeb S, Staal JB, Kennes J, Lamberts PH, de Bie RA. Prevalence of complaints of arm, neck and shoulder among computer office workers and psychometric evaluation of a risk factor questionnaire. BMC Musculoskeletal Disorders 2007; 8: 68-73.

3. Lindfords $P$, von Thiele $U$, Lundberg $U$. Work characteristics and upper extremity disorders in female dental health workers. Journal of Occupational Health 2006; 48; 3: 192-197.

4. Turhan N, Akat C, Akyüz M, Cakci A. Ergonomic risk factors for cumulative trauma disorders in VDU operators. Intnational Journal of Occupational Safety Ergonomics 2008; 14; 4: 417-422.

5. Hannan LM, Monteilh CP, Gerr F, Kleibaum DG, Marcus M. Job strain and risk of musculoskeletal symptoms among a prospective cohort of occupational computer users. Scandinavian Journal of Work and Environmental Health 2005; 3; 15: 375-386.

6. Leroux I, Brisson B, Montreuil S. Job strain and neck-shoulder symptoms: a prevalence study of women and men white-collar workers. Occupational Medicine 2006; 56; 2: 102-109.

7. Vangelova KK, Stanchev VB, Dimitrova LM. Stress and fatigue among technical art staff in radio-production: The role of ergonomic factors and work organization. Bulg J Public Health 2009; 1 (2): 48-58.

8. Vangelova K. The effect of shift schedules on variations of cortisol, fatigue and sleep disturbances in sound engineers. Ind. Health 2008; 46 (5): 490-493.

9. Tzenova B. Characteristics of the work and well-being of employee in the field of services. Bulg $\mathrm{J}$ Publ Health 2009; 1(3): 51-65.

10. Kuorinka I, Jonsson B, Kilbom A, Vinterberg H, Biering-Sørensen F, Andersson G, Jørgensen K. Standardised Nordic questionnaires for the analysis of musculoskeletal symptoms. Applied Ergonomics 1987; 18(3): 233-237.

11. Aarås A, Horgen G, Bjørset HH, Ro O, Walsøe H. Musculoskeletal, visual and psychosocial stress in VDU operators before and after multidisciplinary ergonomic interventions. A 6 years prospective study-Part II. Applied Ergonomics 2001; 32; 6: 559-571.

12. Wong TF, Chow DH, Holmes AD, Cheung KM. The feasibility of repositioning ability as a tool for ergonomic evaluation: effects of chair back inclination and fatigue on head repositioning. Ergonomics 2006; 49; 9: 860-873.

13. Wahlstedt K, Norback D, Wieslander G, Stoglund L, Runeson R. Psychosocial and ergonomic factors, and their relation to musculoskeletal complaints in the Swedish workforce. Int J Occup Safety Ergonomics (JOSE) 2010; 16 (3): 311-321.

14. Rempel D, Willms K, Anshel J, Jaschinski W, Sheedy J. The effects of visual display distance on eye accommodation, head posture, and vision and neck symptoms. Human Factors 2007; 49; 5: 830-838.

15. Reineholm C. Psychosocial Work Conditions and Aspects of Health, Linköping University Medical Dissertations No. 1366, Department of Medical and Health Sciences, Linköping University, Sweden, ISBN 978-91-7519-599-5, Linköping 2013.

\section{Corresponding author:}

Katya Vangelova

National Center of Public Health and Analyses

15 Akad. Ivan Geshov Boul.

$\mathrm{Bg}-1341$ Sofia

e-mail: k.vangelova@ncpha.government.bg 